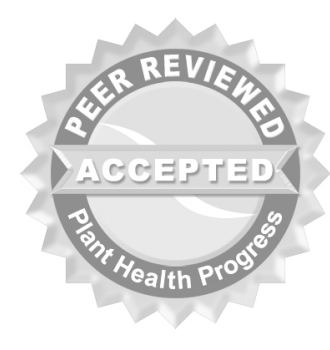

(c) 2013 Plant Management Network.

Accepted for publication 13 November 2013. Published 25 November 2013.

\title{
Ceratobasidium Root Rot: A New Disease of Watermelon in Arizona
}

Claudia Nischwitz, Department of Biology, Utah State University, Logan, UT 84322; Periasamy Chitrampalam, Department of Plant Pathology, North Dakota State University, Fargo, ND 58108; and Mary Olsen, School of Plant Sciences, The University of Arizona, Tucson, AZ 85721

Corresponding author: Claudia Nischwitz. claudia.nischwitz@usu.edu

Nischwitz, C., Chitrampalam, P., and Olsen, M. 2013. Ceratobasidium root rot: A new disease of watermelon (Citrullus lanatus) in Arizona. Online. Plant Health Progress doi:10.1094/PHP-2013-1125-01-BR.

Since spring 2002, young wilting watermelon (Citrullus lanatus) plants were brought to the diagnostic lab at the University of Arizona from several fields in the lower desert of Arizona. The samples were of particular interest since young watermelon plants in Arizona rarely have any root-rot diseases in spring (February-May). The disease in these fields occurred in patches, and roots of affected plants were covered with small brown lesions (Fig. 1). Infected plants in the field were smaller and grew more slowly than healthy plants (Fig. 2). Isolations from root lesions after surface sterilization with $5 \%$ bleach for one minute on $1 / 4$-strength potato dextrose agar (PDA) consistently yielded a fungus morphologically identified as Rhizoctonia spp. For further characterization, three-day-old hyphae were stained using Bandoni's (2) technique, and the nuclear condition was microscopically determined to be binucleate (Fig. 3). We did not observe the perfect stage. The internal transcribed spacer (ITS) region of three isolates grown in liquid 1/4-PDA for 5-7 days was sequenced using the primers ITS4 and ITS5 (4). The closest match of the sequences in a GenBank BLAST search was to a binucleate Rhizoctonia (Ceratobasidium sp.) isolate from strawberries in Israel in anastomosis group AG-F (GenBank accession number: AB219144.1). The ITS sequences of the Arizona isolates were 99.8\% identical with the sequences of the strawberry isolate. A representative ITS sequence from Arizona has been submitted to GenBank (KC140583). A binucleate Rhizoctonia sp. isolate that caused similar symptoms on watermelon in Italy (1) also matched the isolate from Israel. In addition, to the isolates from Italy, Israel, and Arizona, isolates belonging to AG-F have been previously found on cucumber and soybean in the USA and sweet potato and pea in Japan (3). The strains in Arizona may have been present for a long time and may have been misdiagnosed.

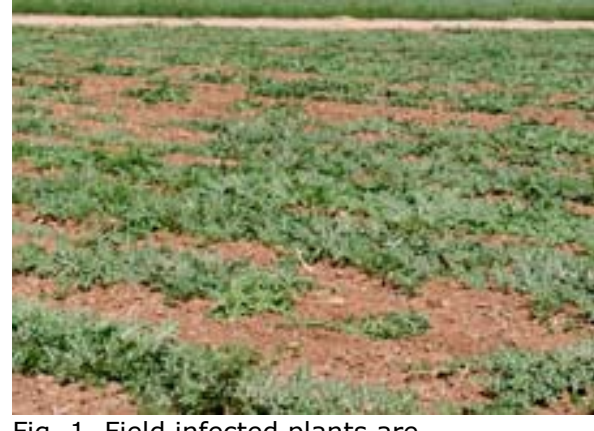

Fig. 1. Field infected plants are comparatively smaller and slower growing than healthy plants.

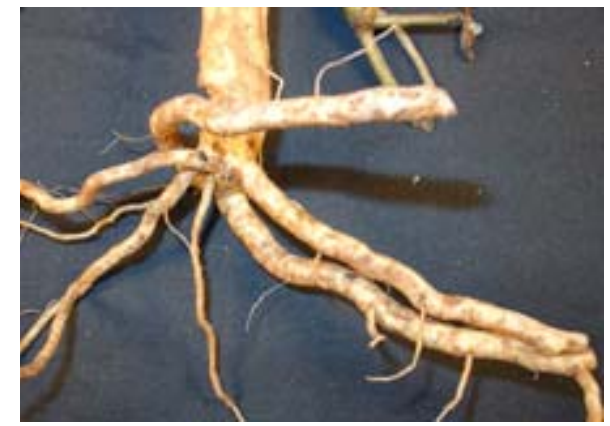

Fig. 2. Roots with light brown lesions over main and secondary roots. 


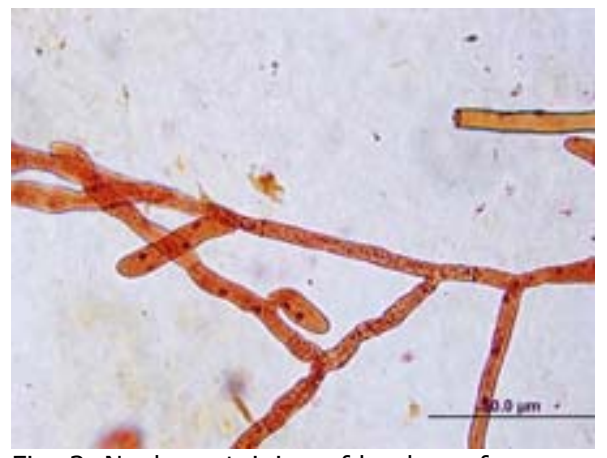

Fig. 3. Nuclear staining of hyphae of binucleate Rhizoctonia ssp. Isolate from watermelon.

To confirm that the isolated Ceratobasidium sp. was the causal agent of the root rot, 'Crimson Sweet' watermelon seedlings were transplanted into 6-inch pots in a potting mix that contained $50 \%$ pasteurized field soil, $25 \%$ vermiculite, and $25 \%$ perlite. At transplanting, the soil was infested with two Ceratobasidium sp. isolates grown on sterile barley seed at $25^{\circ} \mathrm{C}$ for 3 weeks. Each isolates was tested separately for pathogenicity. Pots with sterile, non-infested barley seed were used as controls. After three weeks, the roots of watermelons grown in pots infested with Ceratobasidium sp. showed the characteristic brown lesions, and Ceratobasidium sp. was re-isolated from the lesions. No symptoms were observed on roots of plants grown in control pots. DNA sequencing showed that the re-isolated Ceratobasidium sp. was 100\% identical to the isolates used for inoculations, confirming that Ceratobasidium was the causal agent of the root rot on watermelons.

To our knowledge, Ceratobasidium species have never been previously reported as a pathogen of watermelon anywhere in the United States. The disease was first observed on watermelon in May 2002 near Coolidge, AZ. The field was irrigated by sub-surface drip and had been minimally tilled after barley. In other occurrences in Eloy and Litchfield, AZ, the fields also were irrigated by sub-surface drip but were conventionally tilled and rotated from cotton or potatoes. Both pollinator and seedless varieties were symptomatic in affected fields. This disease has been observed sporadically in different locations over the past 10 years in Arizona, and its impact on yield is unknown. In most cases, plants either remained smaller but with no further symptom development or they recovered as temperatures increased in late May and early June.

However severe losses were reported in Italy from genetically identical isolates, increasing concern about impact of the disease in Arizona. Because of the recent reports in Italy and confirmed incidences in major watermelon production areas in Arizona, this disease should be recognized as a potential problem in watermelon.

\section{Literature Cited}

1. Aiello, D., Vitale, A., Hyakumachi, M., and Polizzi, G. 2012. Molecular characterization and pathogenicity of binucleate Rhizoctonia AG-F associated to the watermelon vine decline in Italy. Eur. J. Plant Pathol. 134:161-165.

2. Bandoni, R. J. 1979. Safranin O as a rapid stain for fungi. Mycologia 71:873-874.

3. Sharon, M., Freeman, S., Kuminaga, S. and Sneh, B. 2007. Genetic diversity, anastomosis groups and virulence of Rhizoctonia spp. from strawberry. Eur. J. Plant Pathol. 117:247-265.

4. White, T. J., Bruns, T., Lee, S., and Taylor, J. 1990. Amplification and direct sequencing of fungal ribosomal RNA genes for phylogenetics. Pages 315-322 in: PCR Protocols: A Guide to Methods and Applications. M. A. Innis, D. H. Gelfand, J. J. Sninsky, and T. J. White, eds. Academic Press, San Diego, CA. 